OPEN ACCESS

Edited by:

Ivan Baccelli,

Istituto per la Protezione sostenibile delle Piante,

Sede Secondaria Firenze,

Italy

Reviewed by:

Silvia Proietti,

Università degli Studi della Tuscia,

Maaria Rosenkranz, Helmholtz Center Munich,

Germany

*Correspondence:

Martin Heil

martin.hei@@investav.mx

Specialty section:

This article was submitted to

Plant Microbe Interactions,

a section of the journal

Frontiers in Plant Science

Received: 08 October 2019

Accepted: 27 January 2020

Published: 25 February 2020

Citation:

Camacho-Coronel X, Molina-Torres $J$ and Heil M (2020) Sequestration of Exogenous Volatiles by Plant Cuticular Waxes as a Mechanism of Passive Associational Resistance:

A Proof of Concept.

Front. Plant Sci. 11:121. doi: $10.3389 /$ fpls.2020.00121

\section{Sequestration of Exogenous Volatiles by Plant Cuticular Waxes as a Mechanism of Passive Associational Resistance: A Proof of Concept}

\author{
Xicotencatl Camacho-Coronel ${ }^{1}$, Jorge Molina-Torres ${ }^{2}$ and Martin Heil ${ }^{1 *}$ \\ ${ }^{1}$ Laboratorio de Ecología de Plantas, CINVESTAV-Irapuato, Departamento de Ingeniería Genética, Irapuato, México, \\ 2 Laboratorio de Fitobioquímica, CINVESTAV-Irapuato, Departamento de Biotecnología y Bioquímica, Irapuato, México
}

Numerous plant-derived volatile organic compounds (VOCs) induce the expression of resistance-related genes and thereby cause an "associational resistance" in neighbouring plants. However, VOCs can also be sequestered by plant cuticular waxes. In case that they maintain their biological activity, such sequestered VOCs could generate a "passive" associational resistance that is independent of any gene expression in the receiver. As a proof of concept, we used major components of the cuticular wax layers of the tree, Parkinsonia praecox, and conidia of Colletotrichum lindemuthianum, a fungal pathogen that has not been reported to infect $P$. praecox. Wax layers were re-constituted on glass slides and exposed to each of 20 pure VOCs for $1 \mathrm{~d}$ and then to ambient air for $1 \mathrm{~d}$ or $15 \mathrm{~d}$. Gas chromatography-mass spectrometry (GC-MS) analyses showed that all 20 VOCs were sequestered by the re-constituted wax layers. Exposure to 18 of the VOCs significantly inhibited the germination of $C$. lindemuthianum conidia on these wax layers after 1 day of exposure to ambient air. Four of the VOCs: 4Z-heptenol, farnesene, limonene, and $2 E$-decenal, inhibited germination rates to less than $25 \%$ of the controls. After $15 \mathrm{~d}$, all VOCs were still detectable, although at strongly reduced concentrations, and no significant inhibition of conidial germination could be detected anymore. Exogenous VOCs can be sequestered by the components of plant cuticular waxes and maintain their biological activity, at least over a certain time span: an effect that could generate a transient "passive associational resistance" to pathogens.

Keywords: antifungal volatiles, antracnosis, cuticle, defense, pathogen, plant disease

\section{INTRODUCTION}

Plants respond to biotic and abiotic stress with the release of a diverse array of VOCs. These VOCs can contribute to the resistance to herbivores and pathogens in the emitting plant itself (Heil, 2014; Ameye et al., 2018), but VOCs are also being discussed to explain the phenomenon of "associational resistance": a resistance effect that is mediated by neighbouring plants (Himanen et al., 2010; Himanen et al., 2015). Associational resistance to herbivores is a frequently described phenomenon and might represent a mechanism that contributes to the beneficial effects of polyculture systems. 
Therefore, VOCs receive increasing interest as a potential tool in biological control (Himanen et al., 2015; Stenberg et al., 2015; Brilli et al., 2019; Mofikoya et al., 2019).

Two commonly discussed mechanisms to explain VOCmediated associational resistance are the induction of resistancerelated traits in the receiver plant (Heil, 2014; Castelyn et al., 2015; Kim, 2017; Ameye et al., 2018; Effah et al., 2019) and the sequestering of exogenous VOCs in plants and their subsequent release into the atmosphere (Himanen et al., 2010; Li and Blande, 2015; Mofikoya et al., 2017). For example, birch (Betula spp.) leaves gained associational resistance $v i a$ the sequestering and re-release of herbivore-repellent VOCs that had been emitted from neighbouring Rhododendron tomentosum plants (Himanen et al., 2010; Himanen et al., 2015), and exogenous VOCs from neighbouring plants affected the preference of the specialist herbivore, Plutella xylostella for its host plant, Brassica oleracea (Li and Blande, 2015). Thus, Himanen \& col suggested that exogenous VOCs can generate a "passive associational resistance" (Himanen et al., 2010; Himanen et al., 2015; Mofikoya et al., 2017). Nevertheless, concerns remain because under ambient conditions, VOCs are quickly diluted, dispersed, oxidised, or degradedparticularly under the influence of wind, ozone, and UV radiation - and thus, VOCs are unlikely to maintain in stable concentrations in the atmosphere (Holopainen and Blande, 2013; Niinemets et al., 2014; Li et al., 2016; Giron-Calva et al., 2017; Holopainen et al., 2017; Mofikoya et al., 2017).

However, the outer surface of the above-ground part of the plants represents a major battleground for plant-microbe interactions (Junker and Tholl, 2013). These surfaces are covered by a matrix collectively designated as (epi)cuticular waxes (Buschhaus and Jetter, 2011): complex mixtures of hydrophobic compounds such as long-chain esters-compounds chemically considered as waxes (Bruice, 2006) - and other lipophilic compounds such as saturated aliphatic hydrocarbon chains of at least 20 carbons, pentacyclic triterpenoids, and phenylpropanoids (Vogg et al., 2004; Kunst and Samuels, 2009; Buschhaus and Jetter, 2011; Hama et al., 2019). Thus, due to the lipophilic nature of these epicuticular waxes, it has been proposed that endogenous VOCs can accumulate in the epicuticular wax layers of plants (Widhalm et al., 2015). However, the same argument applies also to exogenous VOCs, i.e., VOCs that have been emitted from other parts of the plant or from neighbouring plants In fact, endo- and exogenous terpenes were reported from the epicuticular wax matrix of Scots pine (Pinus sylvestris) trees growing in their natural habitat (Joensuu et al., 2016). Many VOCs have antimicrobial effects, at least in vitro. For example, VOCs emitted from pathogenchallenged bean plants inhibited the germination of fungal conidia on leaf surfaces or in vitro (Quintana-Rodriguez et al., 2015; Quintana-Rodriguez et al., 2018b) and VOCs emitted from grapevine cultivars resistant to downy mildew reduced the infection rates of susceptible cultivars and had direct antifungal effects when tested in vitro or using leaf discs (Lazazzara et al., 2018).

Based on the above-mentioned anecdotic evidence showing i) that birch leaves sequestered VOCs from neighbouring Rhododendron tomentosum plants (Himanen et al., 2010) and ii) that plant-derived VOCs directly inhibited the germination of conidia of plant pathogenic fungi such as Botrytis cinerea, Colletotrichum lindemuthianum, Fusarium oxysporum, (Quintana-Rodriguez et al., 2015; Quintana-Rodriguez et al., 2018b) or Plasmopara viticola (Lazazzara et al., 2018), we hypothesized that exogenous VOCs can be sequestered by the cuticular waxes of a receiver plant without losing their antifungal properties and that this mechanism might contribute significantly to a "passive associational resistance" against pathogens, which is independent of any resistance gene expression in the receiver plants. The goal of the present study was to provide a proof of concept for this hypothesis.

To focus on the direct antifungal effects of VOCs-containing waxes and exclude any influences from a receiver plant, we employed an in vitro experimental setup (Figure 1). As a source of major compounds of natural cuticular waxes, we selected the native Mexican plant, Parkinsonia praecox (Ruiz \& Pavon) Hawkins (Fabaceae), which is known for its thick layer of cuticular waxes (Aguilar Rodríguez et al., 2016; Aguilar Rodríguez et al., 2019). As a model pathogen, we chose Colletotrichum lindemuthianum. This fungal pathogen commonly infects bean and other plants within the Fabaceae and has been shown to be sensitive to exogenous VOCs during the initial colonisation of host plants (i.e., during spore germination of the leaf surface, see Quintana-Rodriguez et al., 2015; Quintana-Rodriguez et al., 2018b; Martins et al., 2019). However, C. lindemuthianum is not known to infect $P$. praecox. Hence, it appeared to be unlikely that the cuticular waxes of $P$. praecox contained compounds that have evolved specifically as a defence against this particular pathogen. Layers of cuticular wax compounds were re-constituted on glass slides and exposed to each out of a total of 20 pure VOCs. These VOCs were selected because they have been reported to be emitted from plants (Aggarwal et al., 2002; Huang et al., 2012; Liu et al., 2012; Dudareva et al., 2013; Tao et al., 2014; ul Hassan et al., 2015) and to have antimicrobial activity (Aggarwal et al., 2002; Huang et al., 2012; Liu et al., 2012; Tao et al., 2014; Quintana-Rodriguez et al., 2015; Quintana-Rodriguez et al., 2018b). After subsequent exposure of these wax layers to ambient air for 1 or $15 \mathrm{~d}$, we used gas chromatography-mass spectrometry (GC-MS) to quantify VOCs in the wax layers and spore germination assays to test for antifungal effects of the VOC-containing wax layers. Due to the absence of any plant, or leaf, from the assay system, any inhibitory effect on spore germination observed after 1 or $15 \mathrm{~d}$ could be clearly linked to VOCs that had been sequestered by the compounds in the re-constituted wax layers and remained biologically active over the considered time span.

\section{MATERIALS AND METHODS}

Individual branches of plants of Parkinsonia praecox (Ruiz \& Pavon) Hawkins (Fabaceae) were collected at a natural site in Tlacotepec de Benito Juárez, Puebla, México (18 $38^{\circ} 38.4^{\prime \prime} \mathrm{N}$, $\left.97^{\circ} 42^{\prime} 06.1^{\prime \prime} \mathrm{W}\right)$. The plant species was identified by Silvia Aguilar Rodríguez (Facultad de Estudios Superiores Iztacala, UNAM, México) according to (Burkart and Carter, 1976). The strain 1088 of Colletotrichum lindemuthianum (Sacc. \& Magn.) Briosi \& Cav. 

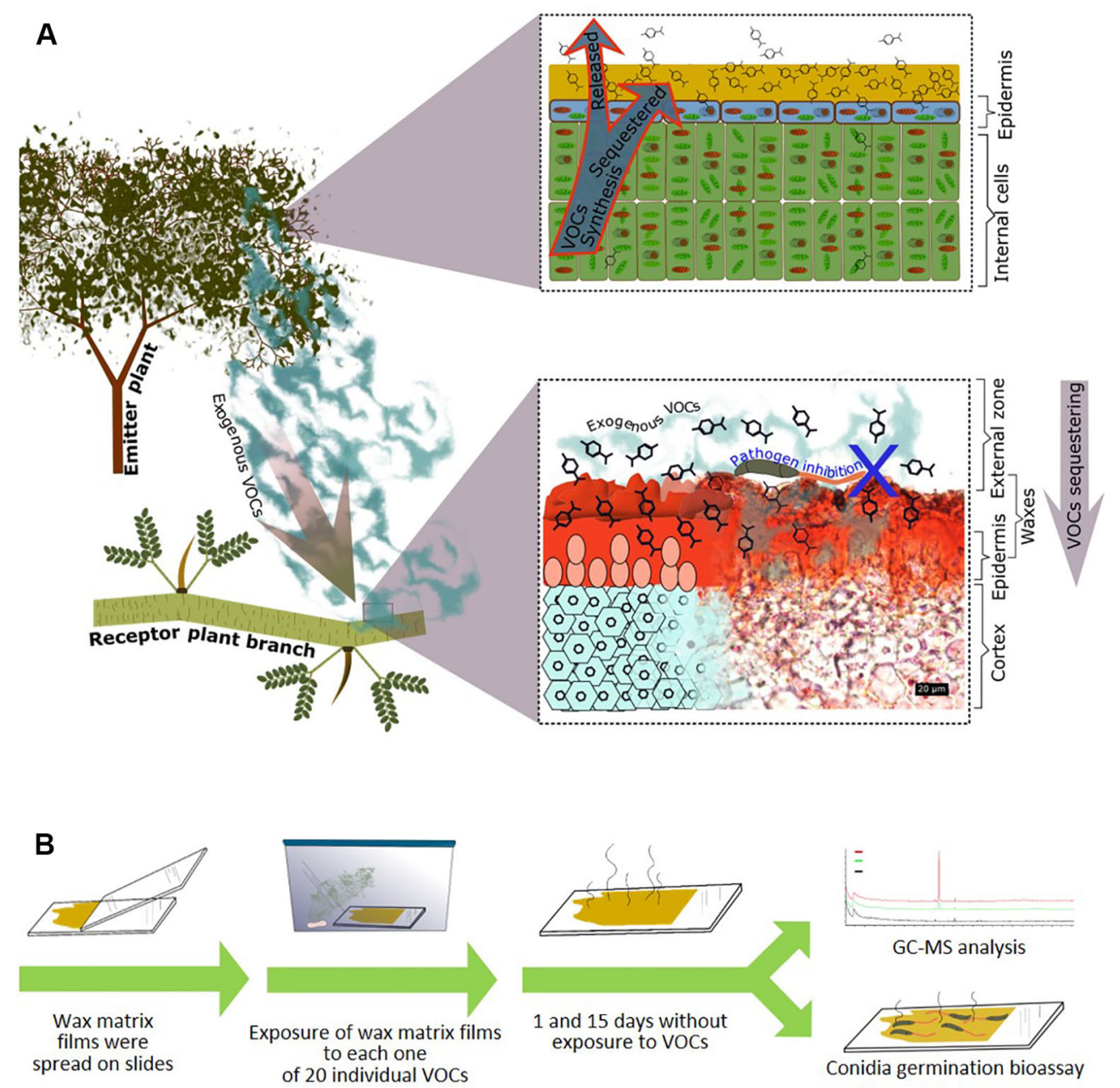

FIGURE 1 | Passive associational resistance: Hypothesis and experimental approach. (A) We propose that -in addition to the endogenous volatile organic compounds (VOCs) that are retained in the cuticular waxes during the emission process (upper panel right side) - also exogenous VOCs can be sequestered by the cuticular waxes of a plant (here: Parkinsonia praecox) and maintain their antimicrobial effects. Lower panel right side: transversal section of a $P$. praecox branch, waxes stained red with Sudan III (photograph donated by Silvia Aguilar Rodríguez). (B) Experimental design: Wax matrix layers were re-constituted on glass slides and then exposed to each out of twenty individual VOCs at a theoretical concentration of $7.142 \mu \mathrm{M}$ in a closed atmosphere. After subsequent exposure to ambient air, the wax layers were randomly assigned to gas chromatography-mass spectrometry (GC-MS) analysis or biotests (germination of conidia of Colletotrichum lindemuthianum).

had been isolated in the state of Durango in México from climbingtype cultivars of bean (González et al., 1998; Luna-Martínez et al., 2006) and was donated by June Kilpatrick Simpson Williamson (CINVESTAV-Irapuato, México). The volatiles 1-octen-3-ol; 2E,4E-nonadienal; $2 E$-hexenyl acetate; 5-hexenyl acetate; $4 Z$ heptenol; $\beta$-caryophyllene; decanal; eugenol; farnesene; heptanal; limonene; linalool; methyl jasmonate; methyl salicylate; ocimene; octanal; terpineol; 2E-decenal; $2 E$-dodecenal; and $2 E$-tridecenal, were purchased at analytical grade from Sigma-Aldrich, St. Louis, Missouri, USA.

Branches of $P$. praecox designated to histochemical analyses (photo in Figure 1A) were fixed in FAA solution (formaldehyde: glacial acetic acid:distilled water:ethanol, 10:5:35:50 v/v) until usage. Transverse sections with $15 \mu \mathrm{m}$ of thicknesses were cut with a rotary microtome and then the sections were stained with Sudan III (Sigma-Aldrich, St. Louis, Missouri, USA), and observed with Leica DM750 microscope (Leica microsystems, Wetzlar, Germany) to detect lipidic compounds.

For the VOC-sequestration analyses, cuticular waxes were removed mechanically from fresh branches by gently scraping the surfaces of the $P$. praecox branches with a scalpel, avoiding damage to the epidermis, weighed and suspended in chloroform (Sigma-Aldrich, St. Louis, Missouri, USA) at $60^{\circ} \mathrm{C}$ to a final concentration of $0.1 \mathrm{~g} \mathrm{ml}^{-1}$ and then filtered through Whatman ${ }^{\circledR}$ qualitative filter paper, Grade 4 . The solvent was evaporated at room temperature to obtain purified wax compounds. To analyse the major compounds in the re-constituted wax layers, $0.15 \mathrm{mg}$ of waxes were dissolved in $1 \mathrm{ml}$ of chloroform containing as an 
internal standard tetracosane at a final concentration of $1 \mu \mathrm{g} \mathrm{Ll}^{-1}$. $500 \mu \mathrm{l}$ of that solution was placed in a $2 \mathrm{ml}$ Eppendorf ${ }^{\circledR}$ tube, the chloroform was evaporated with $\mathrm{N}_{2}$ flux. For derivatization, we added $100 \mu \mathrm{l}$ of bis-N,N-(trimethylsilyl)trifluoroacetamide (BSTFA, Sigma-Aldrich, St. Louis, Missouri, USA) and $100 \mu \mathrm{l}$ of pyridine and incubated $30 \mathrm{~min}$ at $70^{\circ} \mathrm{C}$. The samples were dried and re-dissolved in $200 \mu \mathrm{l}$ chloroform. Analysis was performed using an Agilent 7890 series gas chromatograph interfaced to an Agilent 5975 electronic ionization mass-selective triple axis detector (Agilent Technologies, Santa Clara CA, USA), using the following conditions: HP-5MS column (Agilent 15 X 0.25, 0.25, Agilent Technologies, Palo Alto, CA, USA), injection volume $1 \mu \mathrm{l}$, injection port temperature $270^{\circ} \mathrm{C}$, oven program: initial

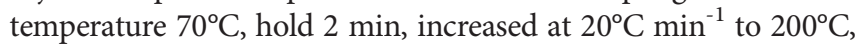
hold $2 \mathrm{~min}$, then increased at $3^{\circ} \mathrm{C} \mathrm{min}^{-1}$ to $310^{\circ} \mathrm{C}$ and hold $30 \mathrm{~min}$. Compounds were preliminarily annotated using NIST MS Search Program v.2.0g, Library version 11 Mass Spectral DataBase, and AMDIS deconvolution software version 2.71 (National Institute of Standards and Technology. US Department of Commerce).

To generate the re-constituted wax layers for VOC sequestration assays, $100 \mathrm{mg}$ waxes were re-suspended in $1 \mathrm{ml}$ of chloroform, and $80 \mu \mathrm{l}$ of this suspension (containing $8 \mathrm{mg}$ of waxes) was spread over an area $\mathrm{ca} 6 \mathrm{~cm}^{2}$ on a glass slide. After solvent evaporation, the slides were introduced individually into $350 \mathrm{~cm}^{3}$ Magenta ${ }^{\mathrm{TM}}$ plant culture boxes (Bioworld, Ohio, USA). The VOCs were dissolved individually in chloroform at $0.05 \mathrm{M}$ and $50 \mu \mathrm{l}$ of this solution was pipetted on a Whatman filter paper disc of $0.5 \mathrm{~cm}$ located in the bottom of the Magenta culture boxes without direct contact with the wax matrix layers. This concentration was chosen based on earlier work (Quintana-Rodriguez et al., 2015). Assuming complete evaporation and no loss or surface adsorption of the VOC, this setup generated a concentration of $7.142 \mu \mathrm{M}$ VOC in the atmosphere of Magenta ${ }^{\mathrm{TM}}$ boxes, which is within the range of VOCs as found in the headspace of resistance-expressing bean plants (Quintana-Rodriguez et al., 2015). Subsequently, the boxes were closed for $24 \mathrm{~h}$. After $24 \mathrm{~h}$, the slides with the wax layers were removed and exposed to ambient air in the laboratory for 1 or $15 \mathrm{~d}$, to then be assigned randomly to either chemical analyses $(n=3$ technical replicates per VOC) or biotests ( $n=7$ biological replicates per VOC).

To quantify the sequestered VOCs, the wax layers were mechanically removed from the glass slides and re-suspended in $200 \mu \mathrm{L}$ of chloroform. Direct analysis was performed using an Agilent 7890 series gas chromatograph interfaced to an Agilent 5975 electronic ionization mass-selective triple axis detector (Agilent Technologies, Santa Clara CA, USA), using the

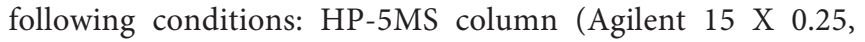
0.25, Agilent Technologies, Palo Alto, CA, USA), injection volume $1 \mu \mathrm{l}$, injection port temperature $180^{\circ} \mathrm{C}$, oven program: initial temperature $60^{\circ} \mathrm{C}$, increased at $5^{\circ} \mathrm{C} \mathrm{min}{ }^{-1}$ to $80^{\circ} \mathrm{C}$ then increased at $8^{\circ} \mathrm{C} \mathrm{min}^{-1}$ to $210^{\circ} \mathrm{C}$ as final temperature. VOCs were identified by comparison of retention times and mass spectra with those of the standard compounds and quantified based on the peak areas, using calibration curves that had been generated using pure compounds at 5 different molar concentrations: $0.005,0.05,0.1,0.25$, and $0.5 \mathrm{mM}$ in chloroform.
To test for the biological activity of the sequestered VOCs, the wax layers on the glass slide were inoculated with conidia of $C$. lindemuthianum. As controls, we used wax layers that had been subjected to the same procedure as described above but exposed to ambient air instead of a VOC headspace. To collect the conidia for the biotests, we poured $2 \mathrm{ml}$ of tween at $0.05 \%$ in distilled water over mycelia of $C$. lindemuthianum that had been cultivated over $15 \mathrm{~d}$ on PDA medium. The resulting suspension was adjusted with distilled water to a concentration of 1 X $10^{7}$ conidia $\mathrm{ml}^{-1}$ (Quintana-Rodriguez et al., 2015), quantified by counting using a hemacytometer (Hausser Scientific, Horsham, Pennsylvania, USA) and a Leica DM750 microscope (Leica microsystems, Wetzlar, Germany) at 40X. The surfaces of the VOC-exposed waxes matrix were inoculated with $50 \mu \mathrm{l}$ of this suspension and introduced into a Petri dish with 2 $\mathrm{ml}$ of distilled water to maintain the humidity. After 48 hours, the slides were stained with lactophenol blue (Sigma-Aldrich, St. Louis, Missouri, USA) to count the germinated and nongerminated spores using the microscope.

\section{RESULTS}

Ten compounds were quantitatively dominant in the chloroformbased preparations of the cuticular waxes of $P$. praecox (Figure 2). Among these ten dominant peaks (Figure 2A), seven compounds were preliminarily identified as triterpenoids (betulin, germanicol, hopenone, lupenone, tocopherol, and derivates of cyclolanostanol, cycloartenol and of oxolanostadienoate), two as alkanes (nonacosane and triacontane), and one as a tocopherol-derivate (Figure 2A, Figure A in the Supplementary Material). Quantitatively, terpenoids compounds made up ca. $85 \%$ of the chloroform-soluble wax matrix (Figure 2B). In total, the preliminary annotation identified > 50 compounds; among these, nine were triterpenoids, 28 alkanes, 16 fatty acids, four alkenes and four alcohols (Figure 2C, Figure B in Supplementary Material).

All 20 tested VOCs were sequestered by the re-constituted wax layers and could be detected at quantities of $0.2-25 \mu \mathrm{mol} \mathrm{g}{ }^{-1}$ wax matrix, after $1 \mathrm{~d}$ of exposure to ambient air, whereas no other VOCs could be detected apart from minor impurities that also appeared in the control wax layers that only had been exposed to ambient air (Figures 3A, B). Fifteen of the VOCs were detected at concentrations $>4 \mu \mathrm{mol} \mathrm{g}{ }^{-1}$, the highest concentrations observed being ca. $25 \mu \mathrm{mol} \mathrm{g}^{-1}$ for $2 E, 4 E$-nonadienal and $21 \mu \mathrm{mol} \mathrm{g}^{-1}$ for $2 E$ decenal. Only farnesene, heptanal, linalool, methyl jasmonate, and ocimene were detected at $<4 \mu \mathrm{mol} \mathrm{g}^{-1}$. All compounds could still be detected after $15 \mathrm{~d}$ exposure to ambient air, although at significantly lower concentrations as compared to day 1 (for all VOCs: $\mathrm{p}<0.05$, $\mathrm{t}$ test, $\mathrm{n}=3$ technical replicates, Figure $3 \mathbf{B}$ ).

Exposure of the wax layers to 18 out of the 20 VOCs significantly inhibited the subsequent germination of $C$. lindemuthianum spores, at least when the re-constituted wax layers were inoculated after $1 \mathrm{~d}$ of exposure to ambient air ( $\mathrm{p}<$ 0.05 , ANOVA and Dunnett test, $\mathrm{n}=7$, Figure 3C). The strongest inhibition-with germination rates $<50 \%$ of the controls-was observed for 2E,4E-nonadienal, $2 E$-hexenyl acetate, $4 Z$-heptenol, 


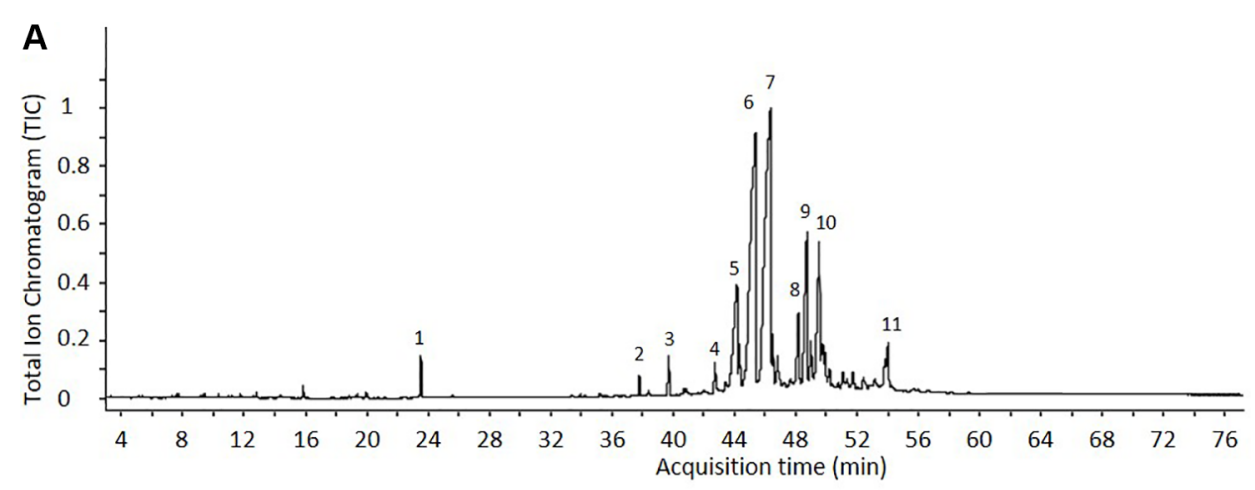

B Relative abundance of compounds

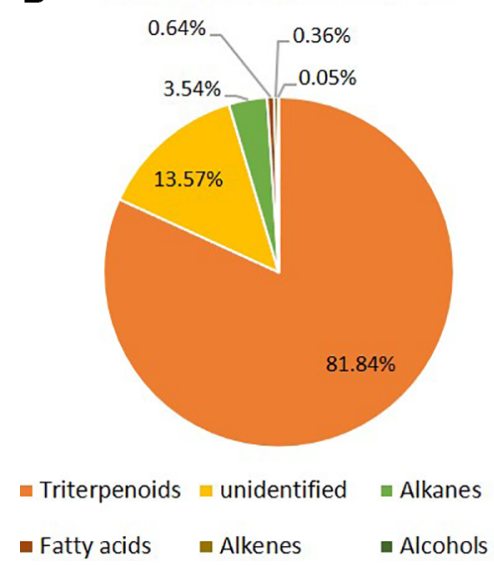

C

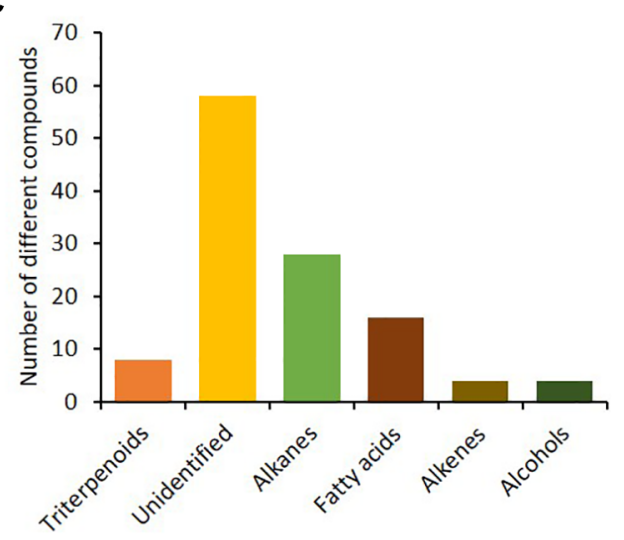

FIGURE 2 | The epicuticular waxes matrix of Parkinsonia praecox contained mainly triterpenoids. (A) Representative chromatogram of compounds from cuticular waxes of $P$. praecox. Preliminary identification of compounds (for retention times and mass spectra, see Figure A, Supplementary Material): 1) tetracosane (internal standard); 2) tocopherol (triterpenoid 1); 3) nonacosane (alkane 1); 4) germanicol (triterpenoid 2); 5), triacontane (alkane 2); 6) hopenone b (triterpenoid 3); 7) lupenone (triterpenoid 4); 8), cyclolanostanol-derivative 1 (triterpenoid 5), 9) oxolanostadienoate-derivative (triterpenoid 6); 10) betulin (triterpenoid 7); and 11) 24methylene-cycloartenol (triterpenoid 8). (B) Relative abundance of the dominant compound classes in wax matrix. (C) Numbers of different compounds (i.e., distinct peaks in the GC-spur) that were assigned to each class of compounds found in the wax matrix (see Figure B, Supplementary Material).

$\beta$-caryophyllene, eugenol, farnesene, limonene, linalool, terpineol, $2 E$-decenal, and $2 E$-tridecenal. Lower, but still significant, inhibition effects (germination rates $50 \%-75 \%$ of controls) were observed for 5-hexenyl acetate, heptanal, ocimene, octanal, and $2 E$-dodecenal, whereas no significant effect could be observed for 1-octen-3-ol and methyl salicylate. However, this inhibitory effect was lost after $15 \mathrm{~d}$ of exposure to ambient air, with the only exception of decanal, which still caused a significant reduction in the proportion of germinated spores $(\mathrm{p}<0.05$, Dunnett test, $\mathrm{n}=7$ biological replicates, Figure 3C).

\section{DISCUSSION}

Associational resistance to herbivores is a frequently described phenomenon. Several studies demonstrated that the sequestration of exogenous VOCs by leaves and their subsequent release into the plant's headspace can contribute to this phenomenon (Himanen et al., 2010; Li and Blande, 2015; Mofikoya et al., 2017). Here, we demonstrate the potential role of cuticular waxes in a passive associational resistance to pathogens that is mediated by exogenous antimicrobial VOCs. We used an in vitro model system consisting of wax layers that had been reconstituted from chloroform-based extracts of the cuticular waxes of $P$. praecox. The detailed analysis of these waxes was beyond the scope of the present work. However, preliminary annotation identified the quantitatively dominating compounds as long-chain alkanes and alkenes and as triterpenoids. Longchained lipophilic compounds, and even triterpenoids such as betulin, germanicol, and tocopherols, are typically reported from the (epi)cuticular waxes of plants (Jetter and Riederer, 1995; Jetter et al., 2006; Racovita and Jetter, 2016; Guo et al., 2017), including from species in the same plant family as $P$. praecox, the Fabaceae (Kim et al., 2007; Regasini et al., 2009; Buschhaus and 

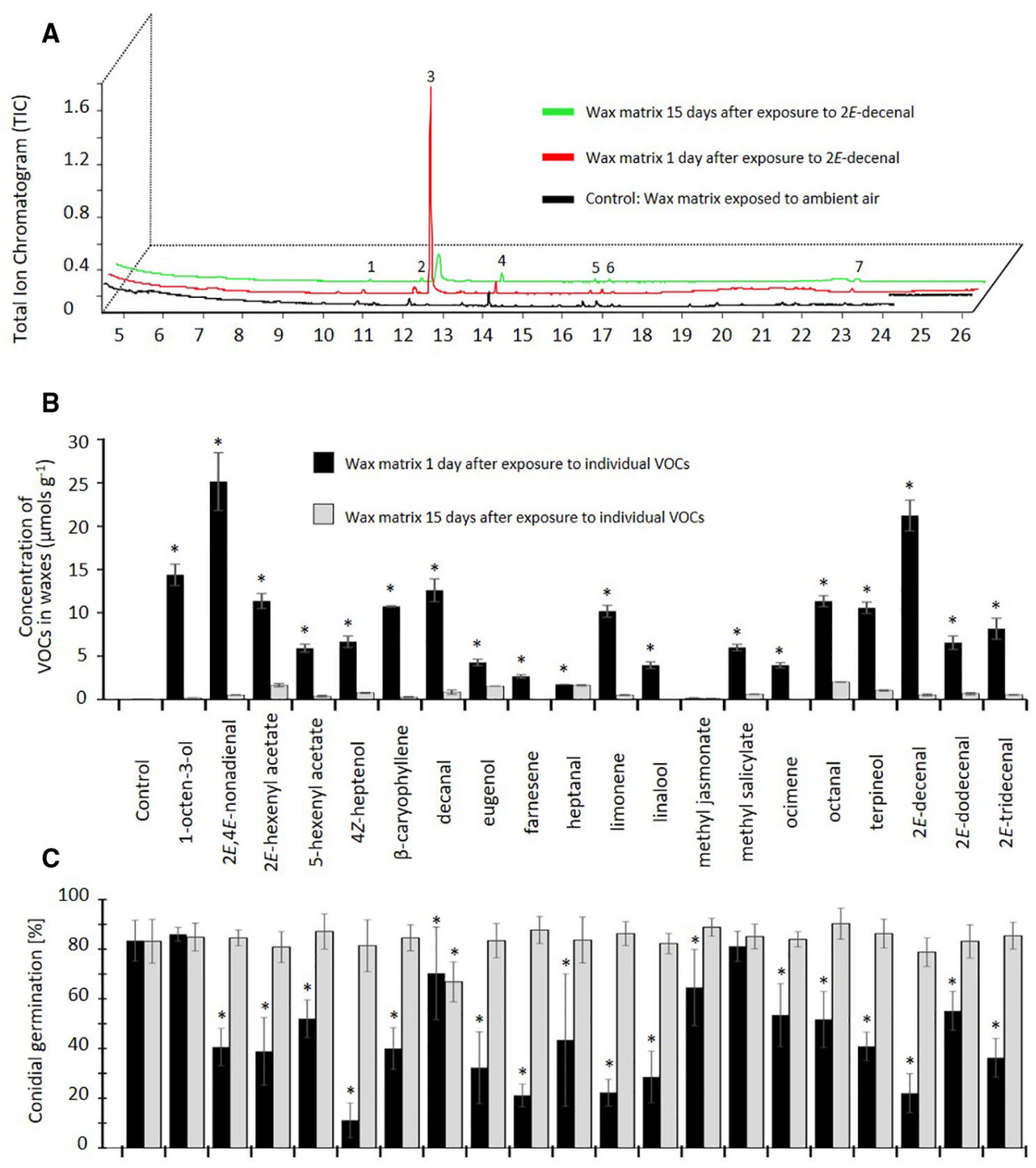

FIGURE 3 | Proof of concept: Volatile organic compounds (VOCs) can be sequestered by epicuticular waxes and maintain their antifungal effect. (A) Chromatograms of epicuticular wax matrices of Parkinsonia praecox exposed to 2Z-decenal and subsequently to ambient air for 1 day (red) or $15 \mathrm{~d}$ (green) or exposed to ambient air only (control: black). Peak numbers: 1,2) not identified; 3) 2Z-decenal; 4) 4-undecanol; 5) 2,6,10,15-tetramethyl-heptadecane; 6) 2,4-bis(1,1dimethylethyl)-phenol; 7) heneicosane. (B) The concentration of VOCs in wax matrices after exposure to at a theoretical concentration of $7.142 \mu \mathrm{M}$ in a closed atmosphere and subsequent exposure to ambient air for 1 day (black bars) or $15 \mathrm{~d}$ (grey bars). Control: wax matrices exposed to ambient air only. Asterisks indicate significant differences between the concentration of sequestered VOC detected at day 1 and day $15(p<0.05, n=3$ technical replicates, t-test. (C) Germination rate of Colletotrichum lindemuthianum conidia on VOC-exposed wax matrices. Asterisks mark germination rates significantly lower than controls $(p<0.05$, Dunnett test, $\mathrm{n}=7$ biological replicates). Bars in (B, C) indicate means, error bars indicate \pm 1 SD.

Jetter, 2011). Long-chained alkanes and alkenes, but also triterpenoids, are typical components of the cuticular wax layers of species from semi-arid climates (Racovita et al., 2015), and triterpenoids even accounted for almost $65 \%$ by mass of the cuticular waxes on heather (Calluna spec.) leaves (Szakiel et al., 2013). The high proportion of triterpenoids indicates that our wax preparations contained components that are more representative of intracuticular waxes (van Maarseveen and Jetter, 2009). However, in general terms, the detected major compounds are frequently reported from plant cuticular wax layers. Thus, we conclude that our re-constituted wax-layers represent a suitable in-vitro model to study whether VOCs could be sequestered by compounds as they are typically found in plant cuticular waxes and maintain their antifungal properties under these conditions.

Indeed, the re-constituted wax-layers sequestered all of the 20 VOCs tested (1-octen-3-ol; 2E,4E-nonadienal; $2 E$-hexenyl acetate; 5 -hexenyl acetate; $4 Z$-heptenol; $\beta$-caryophyllene; decanal; eugenol; farnesene; heptanal; limonene; linalool; methyl jasmonate; methyl salicylate; ocimene; octanal; 
terpineol; 2E-decenal; 2E-dodecenal; and 2E-tridecenal), and these VOCs were still detectable in the wax matrix after $15 \mathrm{~d}$ exposure to ambient air. Moreover, 18 out of 20 VOCs significantly reduced the germination rates of $C$. lindemuthianum conidia on these wax layers, at least after $1 \mathrm{~d}$ exposure to ambient air. This inhibitory effect was lost after $15 \mathrm{~d}$, most likely due to the low concentrations of the remaining sequestered VOC within the wax matrix. Nevertheless, our observations demonstrate that VOCs maintain their antimicrobial activity even when they were sequestered by plant cuticular waxes.

The capacity of this wax matrix to sequester VOCs strongly differed among compounds and the amount of sequestered VOC did not correlate closely with the observed inhibitory effect on the germination of fungal conidia. For example, $2 E, 4 E-$ nonadienal and $2 E$-decenal were detected at highest concentrations in the waxes, whereas lowest germination rates were observed on wax layers that had been exposed to $4 Z$ heptenol, eugenol, farnesene, limonene, linalool, or $2 E$-decenal. By contrast, only traces were detected for methyl jasmonate, but the spore germination on these wax matrices was slightly, but still significantly, inhibited. Finally, a relatively high concentration of decanal after $1 \mathrm{~d}$ was associated with a low inhibition effect, but this effect remained stable even after an almost complete loss of decanal after $15 \mathrm{~d}$. These observations show that further factors need to be considered if we aim to fully understand the anti-fungal activity of plant waxes that had been exposed to exogenous VOCs.

Beyond doubt, the experimental conditions in this study were highly artificial, and several factors should be considered for an adequate interpretation of our observations. First, epicuticular waxes form complex crystal structures (Hama et al., 2019), in particular tubular crystal-like structures that consist mainly of nonacosan-derivatives. These tubular structures easily re-build from wax extracts (Jetter and Riederer, 1995), and nonacosane and triacontane were major compounds in the $P$. praecox wax preparations (Figure 2). Nevertheless, it appears to be unlikely that our re-constituted way layers had maintained a significant part of the natural, three-dimensional structure of $P$. praecox waxes. Therefore, our results indicate that the detailed three-dimensional structures of cuticular waxes are not likely to represent a crucial element for the sequestration of exogenous VOCs. Rather, the localisation of the VOC within the waxes and chemical reactions of the VOCs with other molecules are factors that might explain the low correlation between the amounts of different VOCs and the antimicrobial effects that we observe in our results. For example, VOCs rapidly become oxidised, and the oxidised molecules have much longer lifetimes than the original molecules (Holopainen et al., 2017) yet, they might have completely different effects on fungal pathogens.

Second, several components of plant epicuticular waxes have antimicrobial effects as well (Tholl, 2015), and the waxes used here were obtained from plants in their natural habitat and, thus, might still have contained ambient VOCs from the field site.
Both factors represent potential sources of effects that might have influenced our observations. However, the waxes were obtained from the branches and stems of the plant, long-chained alkanes and triterpenoids are usually considered as transpiration barriers (Oliveira et al., 2003; Buschhaus and Jetter, 2011; Sharma et al., 2018), and to the best of our knowledge, C. lindemuthianum is not a natural pathogen of $P$. praecox. Altogether, these factors make it unlikely that the waxes of $P$. praecox contained any compounds that have specifically co-evolved to resist infection by $C$. lindemuthianum. Moreover, the experimental procedure consisted of two steps of dissolving the waxes matrix and subsequent evaporation, before subjecting the waxes matrix to the bioassays, and as controls we used wax matrix layers that had been subjected to the same procedure but then exposed to ambient air instead of a VOC. Although the appearance of trace amounts of exogenous VOCs in the controls indicates that the ambient air, as expected, was not completely clean, the inhibitory effects observed on the VOC-exposed wax layers were quite strong and statistically robust. Therefore, we conclude that germination rates significantly below those on the control waxes can most likely be attributed to the sequestered VOCs.

Finally, only one concentration of each VOC was used and the concentration of sequestered VOC in the wax layers was only quantified at two time points. Different VOCs strongly differ in their antimicrobial activity on a specific strain. For example, $\beta$ caryophyllene, eugenol, limonene, linalool, and terpineol are frequently reported to inhibit diverse bacterial and fungal strains (Aggarwal et al., 2002; Krist et al., 2007; Krist et al., 2008; Zhou et al., 2014; Pieri et al., 2016; Yoo and Jwa, 2018). Linalool, eugenol, 2E-decenal, terpineol, and citral were the VOCs that most strongly reduced the development of Colletotrichum lindemuthianum, Fusarium oxysporum, Botrytis cinerea in vitro, and methyl jasmonate, limonene and linalool had particularly strong inhibitory effects on the germination of $C$. lindemuthianum on the leaves of bean plants (QuintanaRodriguez et al., 2015; Quintana-Rodriguez et al., 2018a). Therefore, no strict correlation of VOCs concentration in the wax matrix with the inhibitory effect was to be expected, at least not across different types of VOCs.

In summary, future work will be needed to obtain a more complete understanding of the role that VOCs sequestered by epicuticular waxes play in the overall resistance of a plant. More efforts will be required to determine the concentration of VOCs in the headspace of plants under natural conditions: information which would be crucial to determine the level of resistance that plants can gain from sequestered VOCs. Nevertheless, our results show that the exposure of wax-layers to VOCs can generate a transient inhibitory effect on germinating fungal spores that is independent of any putative resistance-related traits in a supporting plant. These antifungal effects of sequestered VOCs that act in the outermost layers of a leaf can represent a further mechanism via which exogenous VOCs contribute to the phenomenon of associational resistance. Therefore, our study serves as a proof of concept that supports a role of exogenous VOCs in the passive associational resistance of plants to pathogens. Our observations also indicate that stable 
concentrations of VOCs in the atmosphere might be less critical for their potential use in biological control than it has been assumed so far. In fact, our observation might not come as a too big surprise, at least not if we consider that waxes and lipids have historically been used to retain aromas: the sequestering of flower scents by waxes represents the basis of a classical technique in perfumery termed 'enfleurage' (Ribechini et al., 2008; Paibon et al., 2011) and served even as the central topic of Patrick Süsskind's novel 'The perfume'. Plants might commonly use 'enfleurage' for their own benefits. Therefore, future studies aimed at understanding associational resistance in plants should consider the potential effects of exogenous and endogenous VOCs that are sequestered by epicuticular waxes.

\section{DATA AVAILABILITY STATEMENT}

The raw data supporting the conclusions of this article will be made available by the authors upon request.

\section{AUTHOR CONTRIBUTIONS}

XC-C, JM-T, and MH conceived the ideas and designed different parts of methodology. XC-C performed the experiments and collected the data. $\mathrm{XC}-\mathrm{C}$ and JM-T analysed the wax and VOC samples, and $\mathrm{XC}-\mathrm{C}$ and $\mathrm{MH}$ wrote the manuscript. All authors contributed critically to the drafts and gave final approval for publication.

\section{REFERENCES}

Aggarwal, K. K., Khanuja, S. P. S., Ahmad, A., Santha Kumar, T. R., Gupta, V. K., and Kumar, S. (2002). Antimicrobial activity profiles of the two enantiomers of limonene and carvone isolated from the oils of Mentha spicata and Anethum sowa. Flavour Fragr. J. 17, 59-63. doi: 10.1002/ffj.1040

Aguilar Rodríguez, S., Terrazas, T., Huidobro-Salas, M. E., and Aguirre-León, E. (2016). Anatomical and histochemical bark changes due to growth of Tillandsia recurvata (ball moss). Bot. Sci. 94, 551-562. doi: 10.17129/botsci.531

Aguilar Rodríguez, S., Terrazas, T., and Camacho-Coronel, X. (2019). A multiple epidermis or a periderm in Parkinsonia praecox (Fabaceae). Turk. J. Bot. 43, 529-537. doi: 10.3906/bot-1810-45

Ameye, M., Allmann, S., Verwaeren, J., Smagghe, G., Haesaert, G., Schuurink, R. C., et al. (2018). Green leaf volatile production by plants: a meta-analysis. New Phytol. 220, 666-683. doi: 10.1111/nph.14671

Brilli, F., Loreto, F., and Baccelli, I. (2019). Exploiting plant volatile organic compounds (VOCs) in agriculture to improve sustainable defense strategies and productivity of crops. Front. Plant Sci. 10, 264. doi: 10.3389/ fpls.2019.00264

Bruice, P. Y. (2006). Essential Organic Chemistry (Upper Saddle River: Pearson Education).

Burkart, A., and Carter, A. (1976). Notas en el género Cercidium (Caesalpinoideae) en Sud América. Darwiniana 20, 305-311. doi: 10.2307/23215725

Buschhaus, C., and Jetter, R. (2011). Composition differences between epicuticular and intracuticular wax substructures: How do plants seal their epidermal surfaces? J. Exp. Bot. 62, 841-853. doi: 10.1093/jxb/erq366

Castelyn, H. D., Appelgryn, J. J., Mafa, M. S., Pretorius, Z. A., and Visser, B. (2015). Volatiles emitted by leaf rust infected wheat induce a defence response in exposed uninfected wheat seedlings. Australas. Plant Pathol. 44, 245-254. doi: 10.1007/s13313-014-0336-1

\section{FUNDING}

This work was economically supported by CONACYT de México and by institutional support from CINVESTAV Unidad Irapuato. The funders had no influence in the planning or execution of the research, the analysis of data or their presentation. $\mathrm{MH}$ and $\mathrm{XC}-\mathrm{C}$ gratefully acknowledge financial support from CONACYT (grants 258119 to $\mathrm{MH}$ and 429106 to XC-C).

\section{ACKNOWLEDGMENTS}

The authors thank Rosa María Adame-Álvarez for help with the experiments, Silvia Aguilar-Rodríguez for help with the determination of $P$. praecox and for donating the photo that forms part of Figure 1A and June Kilpatrick Simpson for donating the strain of $C$. lindemuthianum. We are grateful to the two referees, Silvia Proietti and Maaria Rosenkranz for valuable comments on an earlier version of this manuscript. $\mathrm{MH}$ and XC-C gratefully acknowledge financial support from CONACYT (grants 258119 and 429106).

\section{SUPPLEMENTARY MATERIAL}

The Supplementary Material for this article can be found online at: https:/www.frontiersin.org/articles/10.3389/fpls.2020.00121/ full\#supplementary-material

Dudareva, N., Klempien, A., Muhlemann, J. K., and Kaplan, I. (2013). Biosynthesis, function and metabolic engineering of plant volatile organic compounds. New Phytol. 198, 16-32. doi: 10.1111/nph.12145

Effah, E., Holopainen, J. K., and McCormick, A. C. (2019). Potential roles of volatile organic compounds in plant competition. Perspect. Plant Ecol. Evol. Syst. 38, 58-63. doi: 10.1016/j.ppees.2019.04.003

Giron-Calva, P. S., Li, T., and Blande, J. D. (2017). Volatile-mediated interactions between cabbage plants in the field and the impact of ozone pollution. J. Chem Ecol. 43, 339-350. doi: 10.1007/s10886-017-0836-x

González, M., Rodríguez, R., Zavala, M. E., Jacobo, J. L., Hernández, F., Acosta, J., et al. (1998). Characterization of mexican isolates of Colletotrichum lindemuthianum by using differential cultivars and molecular markers. Phytopathology 88, 292-299. doi: 10.1094/phyto.1998.88.4.292

Guo, Y. J., Busta, L., and Jetter, R. (2017). Cuticular wax coverage and composition differ among organs of taraxacum officinale. Plant Physiol. Biochem. 115, 372 379. doi: 10.1016/j.phytochem.2016.06.005

Hama, T., Seki, K., Ishibashi, A., Miyazaki, A., Kouchi, A., Watanabe, N., et al. (2019). Probing the molecular structure and orientation of the leaf surface of Brassica oleracea L. by polarization modulation-infrared reflection-absorption spectroscopy. Plant Cell Physiol. 60, 1567-1580. doi: 10.1093/pcp/pcz063

Heil, M. (2014). Herbivore-induced plant volatiles: targets, perception and unanswered questions. New Phytol. 204, 297-306. doi: 10.1111/nph.12977

Himanen, S. J., Blande, J. D., Klemola, T., Pulkkinen, J., Heijari, J., and Holopainen, J. K. (2010). Birch (Betula sp.) leaves adsorb and re-release volatiles specific to neighbouring plants-a mechanism for associational herbivore resistance? New Phytol. 186, 722-732. doi: 10.1111/j.1469-8137. 2010.03220.x

Himanen, S. J., Bui, T. N. T., Maja, M. M., and Holopainen, J. K. (2015). Utilizing associational resistance for biocontrol: impacted by temperature, supported by indirect defence. BMC Ecol. 15, 16. doi: 10.1186/s12898-015-0048-6 
Holopainen, J., and Blande, J. (2013). Where do herbivore-induced plant volatiles go? Front. Plant Sci. 4, 185. doi: 10.3389/fpls.2013.00185

Holopainen, J. K., Kivimäenpää, M., and Nizkorodov, S. A. (2017). Plant-derived secondary organic material in the air and ecosystems. Trends Plant Sci. 22, 744-753. doi: 10.1016/j.tplants.2017.07.004

Huang, M., Sanchez-Moreiras, A. M., Abel, C., Sohrabi, R., Lee, S., Gershenzon, J., et al. (2012). The major volatile organic compound emitted from Arabidopsis thaliana flowers, the sesquiterpene (E)- $\beta$-caryophyllene, is a defense against a bacterial pathogen. New Phytol. 193, 997-1008. doi: 10.1111/j.14698137.2011.04001.x

Jetter, R., and Riederer, M. (1995). In vitro reconstitution of epicuticular wax crystals: formation of tubular aggregates by long-chain secondary alkanediols. Bot. Acta 108, 111-120. doi: 10.1111/j.1438-8677.1995.tb00840.x

Jetter, R., Kunst, L., and Samuels, A. L. (2006). "Composition of plant cuticular waxes," in Biology of the plant cuticle, eds. M. Riederer and C. Müller (Chennai: Blackwell Publishing), 145-181.

Joensuu, J., Altimir, N., Hakola, H., Rostás, M., Raivonen, M., Vestenius, M., et al. (2016). Role of needle surface waxes in dynamic exchange of mono- and sesquiterpenes. Atmos. Chem. Phys. 16, 7813-7823. doi: 10.5194/acp-16-78132016

Junker, R. R., and Tholl, D. (2013). Volatile organic compound mediated interactions at the plant-microbe interface. J. Chem. Ecol. 39, 810-825. doi: 10.1007/s10886-013-0325-9

Kim, K. S., Park, S. H., Kim, D. K., and Jenks, M. A. (2007). Influence of water deficit on leaf cuticular waxes of soybean (Glycine max [L.] Merr.). Int. J. Plant Sci. 168, 307-316. doi: 10.1086/510496

Kim, T. N. (2017). How plant neighborhood composition influences herbivory: testing four mechanisms of associational resistance and susceptibility. PLoS One 12, e0176499. doi: 10.1371/journal.pone.0176499

Krist, S., Halwachs, L., Sallaberger, G., and Buchbauer, G. (2007). Effects of scents on airborne microbes, part I: thymol, eugenol, trans-cinnamaldehyde and linalool. Flavour Fragr. J. 22, 44-48. doi: 10.1002/ffj.1750

Krist, S., Sato, K., Glasl, S., Hoeferl, M., and Saukel, J. (2008). Antimicrobial effect of vapours of terpineol, (R)-(-)-linalool, carvacrol, (S)-(-)-perillaldehyde and 1,8-cineole on airborne microbes using a room diffuser. Flavour Fragr. J. 23, 353-356. doi: $10.1002 /$ ffj. 1893

Kunst, L., and Samuels, L. (2009). Plant cuticles shine: advances in wax biosynthesis and export. Curr. Opin. Plant Biol. 12, 721-727. doi: 10.1016/ j.pbi.2009.09.009

Lazazzara, V., Bueschl, C., Parich, A., Pertot, I., Schuhmacher, R., and Perazzolli, M. (2018). Downy mildew symptoms on grapevines can be reduced by volatile organic compounds of resistant genotypes. Sci. Rep. 8, 1618. doi: 10.1038/ s41598-018-19776-2

Li, T., and Blande, J. D. (2015). Associational susceptibility in broccoli: mediated by plant volatiles, impeded by ozone. Glob. Chang Biol. 21, 1993-2004. doi: $10.1111 / \mathrm{gcb} .12835$

Li, T., Blande, J. D., and Holopainen, J. K. (2016). Atmospheric transformation of plant volatiles disrupts host plant finding. Sci. Rep. 6, 33851. doi: 10.1038/ srep33851

Liu, K., Chen, Q., Liu, Y., Zhou, X., and Wang, X. (2012). Isolation and biological activities of decanal, linalool, valencene, and octanal from sweet orange oil. $J$. Food Sci. 77, C1156-C1161. doi: 10.1111/j.1750-3841.2012.02924.x

Luna-Martínez, F., Rodríguez-Guerra, R., Victoria-Campos, M., and Simpson, J. (2006). Development of a molecular genetic linkage map for Colletotrichum lindemuthianum and segregation analysis of two avirulence genes. Curr. Genet. 51, 109-121. doi: 10.1007/s00294-006-0111-0

Martins, S. J., Faria, A. F., Pedroso, M. P., Cunha, M. G., Rocha, M. R., and Medeiros, F. H. V. (2019). Microbial volatiles organic compounds control anthracnose (Colletotrichum lindemuthianum) in common bean (Phaseolus vulgaris L.). Biol. Control 131, 36-42. doi: 10.1016/j.biocontrol.2019.01.003

Mofikoya, A. O., Kim, T. H., Abd El-Raheem, A. M., Blande, J. D., Kivimäenpää, M., and Holopainen, J. K. (2017). Passive adsorption of volatile monoterpene in pest control: aided by proximity and disrupted by ozone. J. Agric. Food Chem. 65, 9579-9586. doi: 10.1021/acs.jafc.7b03251

Mofikoya, A. O., Bui, T. N. T., Kivimaenpaa, M., Holopainen, J. K., Himanen, S. J., and Blande, J. D. (2019). Foliar behaviour of biogenic semi-volatiles: potential applications in sustainable pest management. Arthropod Plant Interact. 13, 193-212. doi: 10.1007/s11829-019-09676-1
Niinemets, Ü., Fares, S., Harley, P., and Jardine, K. J. (2014). Bidirectional exchange of biogenic volatiles with vegetation: emission sources, reactions, breakdown and deposition. Plant Cell Environ. 37, 1790-1809. doi: 10.1111/ pce. 12322

Oliveira, A. F. M., Meirelles, S. T., and Salatino, A. (2003). Epicuticular waxes from Caatinga and Cerrado species and their efficiency against water loss. An. Acad. Bras. Ciênc. 75, 431-439. doi: 10.1590/S0001-37652003000400003

Paibon, W., Yimnoi, C.-A., Tembab, N., Boonlue, W., Jampachaisri, K., Nuengchamnong, N., et al. (2011). Comparison and evaluation of volatile oils from three different extraction methods for some Thai fragrant flowers. Int. J. Cosmet. Sci. 33, 150-156. doi: 10.1111/j.1468-2494.2010.00603.x

Pieri, F. A., Souza, M., Vermelho, L. L. R., Vermelho, M. L. R., Perciano, P. G., Vargas, F. S., et al. (2016). Use of $\beta$-caryophyllene to combat bacterial dental plaque formation in dogs. BMC Vet. Res. 12, 216. doi: 10.1186/s12917-0160842-1

Quintana-Rodriguez, E., Morales-Vargas, A. T., Molina-Torres, J., ÁdameAlvarez, R. M., Acosta-Gallegos, J. A., and Heil, M. (2015). Plant volatiles cause direct, induced and associational resistance in common bean to the fungal pathogen Colletotrichum lindemuthianum. J. Ecol. 103, 250-260. doi: 10.1111/1365-2745.12340

Quintana-Rodriguez, E., Duran-Flores, D., Heil, M., and Camacho-Coronel, X. (2018a). Damage-associated molecular patterns (DAMPs) as future plant vaccines that protect crops from pests. Sci. Hortic. 237, 207-220. doi: 10.1016/j.scienta.2018.03.026

Quintana-Rodriguez, E., Rivera-Macias, L.E., Adame-Alvarez, R. M., Torres, J. M., and Heil, M. (2018b). Shared weapons in fungus-fungus and fungus-plant interactions? volatile organic compounds of plant or fungal origin exert direct antifungal activity in vitro. Fungal Ecol. 33, 115-121. doi: 10.1016/j.funeco.2018.02.005

Racovita, R. C., and Jetter, R. (2016). Composition of the epicuticular waxes coating the adaxial side of Phyllostachys aurea leaves: identification of verylong-chain primary amides. Phytochemistry 130, 252-261. doi: 10.1016/ j.phytochem.2016.06.005

Racovita, R. C., Peng, C., Awakawa, T., Abe, I., and Jetter, R. (2015). Very-longchain 3-hydroxy fatty acids, 3-hydroxy fatty acid methyl esters and 2-alkanols from cuticular waxes of Aloe arborescens leaves. Phytochemistry 113, 183-194. doi: 10.1016/j.phytochem.2014.08.005

Regasini, L. O., Vieira, G. M., Fernandes, D. C., Bolzani, V. D., Cavalheiro, A. J., and Silva, D. H. (2009). Identification of triterpenes and sterols from pterogyne nitens (fabaceae-caesalpinioideae) using high-resolution gas chromatography. J. Chil. Chem. Soc 54, 218-221. doi: 10.4067/s0717-97072009000300004

Ribechini, E., Modugno, F., Colombini, M. P., and Evershed, R. P. (2008). Gas chromatographic and mass spectrometric investigations of organic residues from Roman glass unguentaria. J. Chrom. A 1183, 158-169. doi: 10.1016/ j.chroma.2007.12.090

Sharma, P., Kothari, S. L., Rathore, M., and Gour, V. (2018). Properties, variations, roles, and potential applications of epicuticular wax: a review. Turk. J. Bot. 42, 135-149. doi: 10.3906/bot-1702-25

Stenberg, J. A., Heil, M., Åhman, I., and Björkman, C. (2015). Optimizing crops for biocontrol of pests and disease. Trends Plant Sci. 20, 698-712. doi: 10.1016/ j.tplants.2015.08.007

Szakiel, A., Nizynski, B., and Paczkowski, C. (2013). Triterpenoid profile of flower and leaf cuticular waxes of heather Calluna vulgaris. Nat. Prod. Res. 27, 14041407. doi: $10.1080 / 14786419.2012 .742083$

Tao, N., Jia, L., Zhou, H., and He, X. (2014). Effect of octanal on the mycelial growth of Penicillium italicum and P. digitatum. World J. Microbiol. Biotechnol. 30, 1169-1175. doi: 10.1007/s11274-013-1539-2

Tholl, D. (2015). "Biosynthesis and biological functions of terpenoids in plants," in Biotechnology of Isoprenoids, vol. 63-106 . Eds. J. Schrader and J. Bohlmann (Cham: Springer International Publishing).

ul Hassan, M. N., Zainal, Z., and Ismail, I. (2015). Green leaf volatiles: biosynthesis, biological functions and their applications in biotechnology. Plant Biotechnol. J. 13, 727-739. doi: 10.1111/pbi.12368

van Maarseveen, C., and Jetter, R. (2009). Composition of the epicuticular and intracuticular wax layers on Kalanchoe daigremontiana (Hamet et Perr. de la Bathie) leaves. Phytochemistry 70, 899-906. doi: 10.1016/j.phytochem.2009.04.011

Vogg, G., Fischer, S., Leide, J., Emmanuel, E., Jetter, R., Levy, A. A., et al. (2004). Tomato fruit cuticular waxes and their effects on transpiration barrier properties: functional characterization of a mutant deficient in a very-long- 
chain fatty acid $\beta$-ketoacyl-CoA synthase. J. Exp. Bot. 55, 1401-1410. doi: $10.1093 /$ jxb/erh 149

Widhalm, J. R., Jaini, R., Morgan, J. A., and Dudareva, N. (2015). Rethinking how volatiles are released from plant cells. Trends Plant Sci. 20, 545-550. doi: 10.1016/j.tplants.2017.09.001

Yoo, H.-J., and Jwa, S.-K. (2018). Inhibitory effects of $\beta$-caryophyllene on Streptococcus mutans biofilm. Arch. Oral Biol. 88, 42-46. doi: 10.1016/j.archoralbio.2018.01.009

Zhou, H., Tao, N., and Jia, L. (2014). Antifungal activity of citral, octanal and $\alpha-$ terpineol against Geotrichum citri-aurantii. Food Control 37, 277-283. doi: 10.1016/j.foodcont.2013.09.057
Conflict of Interest: The authors declare that the research was conducted in the absence of any commercial or financial relationships that could be construed as a potential conflict of interest.

Copyright $\odot 2020$ Camacho-Coronel, Molina-Torres and Heil. This is an open-access article distributed under the terms of the Creative Commons Attribution License (CC $B Y$ ). The use, distribution or reproduction in other forums is permitted, provided the original author(s) and the copyright owner(s) are credited and that the original publication in this journal is cited, in accordance with accepted academic practice. No use, distribution or reproduction is permitted which does not comply with these terms. 